\title{
EDUCAÇÃO INFANTIL NOS DESDOBRAMENTOS DO PROCESSO DE INCLUSÃO: PERSPECTIVAS DE PROFESSORES E EQUIPE GESTORA
}

\author{
Luana Cardoso da Silva \\ Universidade Federal de Santa Maria, Brasil. \\ Graziela Escandiel de Lima \\ Universidade Federal de Santa Maria, Brasil.
}

\begin{abstract}
Resumo
Neste trabalho propomos demonstrar e discutir como ocorre o processo de inclusão na educação infantil numa escola do município de Santa Maria, destacando o olhar dos docentes e da equipe diretiva da escola a respeito deste processo. Para tal, foram elaborados dois tipos de questionários, um voltado para o corpo docente da instituição e outro para a equipe gestora. No início do trabalho há uma retomada sobre o processo de inclusão e o universo da educação infantil. A apreciação dos dados dos questionários traz a necessidade da reflexão e a suma importância de, para além desta, avaliarmos cotidianamente nossa prática e atitudes na sala de aula.
\end{abstract}

Palavras-chave: inclusão, educação infantil, políticas públicas.

\section{CHILDOOD EDUCATION IN THE UNFOLDING OF THE PROCESS OF INCLUSION: PERSPECTIVES OF TEACHERS AND MANAGEMENT TEAM}

\begin{abstract}
We proposed to demonstrate and discuss how is the process of inclusion in early childhood education in a school in the city of Santa Maria, highlighting the look of the staff of the school regarding this process. To this end, were developed two types of questionnaires, one facing the teaching staff of the institution and the other to the management team. At the beginning of the work there is a resumption of the process of inclusion and the universe of Early Childhood Education. The examination of data from the questionnaires brings the necessity of reflection and of paramount importance beyond, assessing our daily practice and attitudes within the classroom. Key-words: inclusion, early childhood education, public policies.
\end{abstract}




\section{Introdução}

$\mathrm{O}$ processo de inclusão é uma realidade cada vez mais frequente em nossas escolas regulares e se estabelece como um movimento em prol do direito das crianças com necessidades especiais de experienciar e vivenciar trocas com as demais crianças. A educação infantil é a primeira etapa da educação básica e tem como um de seus objetivos os primeiros passos da socialização dos pequenos fora de suas casas.

Oportunizar que as crianças com necessidades especiais adentrem no ambiente da educação infantil desde os primeiros anos de vida proporcionará a elas um desenvolvimento mais pleno em relação a outras crianças que possuam estas necessidades e que não convivam e interajam com outras crianças de sua faixa etária, visto que ficam por muitas vezes em casa, sem viver a riqueza que essa etapa da educação escolar pode vir a proporcionar.

Muitas políticas que garantem ao aluno especial o direito de freqüentarem a classe regular estão dispostas para conhecimento. Na Declaração da Salamanca encontra-se destacada a importância de uma escola normal no desenvolvimento do aluno com necessidade especial:

As escolas regulares, seguindo esta orientação inclusiva, constituem os meios mais capazes para combater as atitudes discriminatórias, criando comunidades abertas e solidárias, construindo uma sociedade inclusiva e atingindo a educação para todos; além disso, proporcionam uma educação adequada à maioria das crianças e promovem a eficiência, numa óptima relação custo-qualidade, de todo o sistema educativo. (Unesco, 1994, p. IX)

A política nacional de educação especial na perspectiva da educação inclusiva pondera algumas variáveis para o processo inclusivo. Orienta-se que os sistemas de ensino garantam

transversalidade da educação especial desde a educação infantil até o ensino superior; atendimento educacional especializado; continuidade da escolarização nos níveis mais elevados do ensino; formação de professores para $\mathrm{o}$ atendimento educacional especializado e demais profissionais da educação para a inclusão escolar; participação da família e da comunidade; acessibilidade urbanística, arquitetônica, nos mobiliários e equipamentos, nos transportes, na comunicação e informação; articulação intersetorial na implementação das políticas públicas. (Brasil, 2010, p. 19)

No enquadramento da ação evidencia a postura que a escola precisa tomar no processo da educação inclusiva:

As escolas terão de encontrar formas de educar com sucesso estas crianças, incluindo aquelas que apresentam incapacidades graves. Existe o consenso crescente de que as crianças e jovens com necessidades educativas especiais devem ser incluídos nas estruturas educativas destinadas à maioria das crianças, o que conduzi u ao conceito da escola inclusiva O desafio com que se confronta esta escola inclusiva é o de ser capaz de desenvolver uma pedagogia centrada nas crianças, susceptível 
de as educar a todas com sucesso, incluído as que apresentam graves incapacidades. (Unesco, 1994, p. 6)

Ainda podemos contemplar outras leis que garantem os direitos dos alunos com necessidades especiais destacando, dentre elas, a Constituição Federal de 1988, a Lei das Diretrizes e Bases da Educação (1996), o Plano de Desenvolvimento da Educação (2007), o Estatuto da Criança e Adolescente (1990), as Diretrizes Nacionais para a Educação Especial na Educação Básica (2001). Estas leis precisam ser mais conhecidas pelo corpo docente das escolas.

Para tanto, necessita-se uma escola que pense em ofertar possibilidades e alternativas que venham ao encontro dos anseios de todo o seu corpo discente e que busque, incessantemente, o melhor modo de se construir uma escola inclusiva que estabeleça o processo de inclusão.

Dessa forma, faz-se necessário investigar como acontece o processo de inclusão das crianças com necessidades especiais no contexto da educação infantil em uma escola municipal de Santa Maria/RS, tendo como sujeitos da pesquisa os professores que tenham alunos incluídos em suas turmas e os gestores, tentando vislumbrar como estes compreendem o processo de inclusão e as políticas públicas que abordam esta temática.

\section{Contornos investigativos}

No momento em que se pensa nos caminhos efetivos da pesquisa, a definição dos contornos da investigação se torna primordial para um trabalho efetivo com os dados obtidos no campo de pesquisa.

Neste trabalho, que tem como intuito conhecer como ocorre o processo de inclusão dentro de um espaço de educação infantil, tem-se como relevante a escolha pela abordagem qualitativa pelo fato desta se focar mais no sujeito e em uma perspectiva de análise contextual e descritiva dos dados.

Lúdke e André (1986) exemplificam a pesquisa qualitativa como aquela que "envolve a obtenção de dados descritivos, obtidos no contato direto do pesquisador com a situação estudada, enfatiza mais o processo do que o produto e se preocupa em retratar a perspectiva dos participantes" (p. 13).

Dentro da abordagem qualitativa, optou-se pelo estudo de caso, pois, este avalia o contexto, a realidade que será estudada. Para a coleta de dados foram aplicados dois questionários, um destinado as docentes das turmas de uma escola municipal de educação infantil do município de Santa Maria, RS, que tinham crianças com necessidades especiais, e outro para a equipe gestora da mesma.

\section{Importância da inclusão e da educação infantil no desenvolvimento da criança}

$\mathrm{Na}$ Constituição Federal de 1988 percebe-se, no artigo 205, referente a educação que esta é "direito de todos e dever do Estado e da família, será promovida e incentivada com a colaboração da sociedade, visando ao pleno desenvolvimento da pessoa". Visto desta forma, todos os sujeitos têm direito a educação em qualquer etapa de ensino, independente de possuir ou não uma necessidade especial.

A educação infantil e o movimento de inclusão há pouco tempo têm tido destaque e sendo pensados com outro olhar. Políticas públicas foram criadas como forma de garantir 
o acesso da criança à educação infantil e das escolas regulares de receberem um aluno com necessidade especial.

O movimento inclusivo no início não foi visto nem pelos próprios especialistas da área com bons olhos. Temia-se que ocorresse o processo inverso do objetivo, ou seja, a exclusão dos alunos especiais na classe regular.

A seguir tecem-se algumas considerações do que representa o processo de inclusão e o espaço da educação infantil, permitindo fazermos uma reflexão acerca da importância de ambas e como se torna relevante que esse processo de inclusão se inicie na tenra idade, ou seja, na educação infantil.

\section{O movimento de inclusão}

A palavra incluir no dicionário refere-se ao ato de abranger, compreender, envolver, implicar. A palavra inclusão refere-se ao ato ou efeito de incluir. Observando estas palavras podemos contemplar o significado que desejamos ao processo de inclusão. Quando dirigimos ao processo de inclusão em relação à educação, temos como objetivos abranger todas as crianças ao ambiente escolar, nos envolvermos ao máximo nesse processo aprimorando nossos saberes e conhecimentos em busca de que a criança com necessidade especial sinta-se bem amparada e acolhida na escola regular, com o sentimento de pertença e não de exclusão. Isso implica comprometimento de todas as partes para que o processo de inclusão tenha sucesso em seus objetivos, ou seja, de professores, equipe gestora, alunos, pais, comunidade escolar e órgãos governamentais trabalhando juntos.

O processo de inclusão começou a destacar-se com a Constituição Federal de 1988, que prevê a igualdade de direitos a todos, ao Encontro de Jomtien (1990) e de Dakar (2000) que objetivaram reduzir as desigualdades entre os sujeitos. Dessa forma, o processo de inclusão precisa ser entendido como uma proposta que concebe uma responsabilidade compartilhada de todos dentro da instituição escolar, que tem como objetivo o bem-estar do aluno.

Desde 2001 o Brasil teve um grande salto no processo de inclusão com o Plano Nacional de Educação. Macêdo (2008, p.1):

A Lei $n^{\circ} 10.172$, de 9 de janeiro de 2001, que aprova o Plano Nacional de Educação. O capítulo 8 do PNE é destinado à Educação Especial. Este formação sobre ao assunto documento tece um diagnóstico e traça as diretrizes, objetivos e metas para os próximos 10 anos. Segundo o PNE, a oferta de educação especial poderá ser realizada de três formas: participação nas classes comuns, sala especial e escola especial. Sendo que, as salas e escolas especiais devem ser apenas para aqueles que realmente não puderem ser atendidas nas salas convencionais. Neste sentido, a matrícula destes alunos vem crescendo a olhos vistos entre 1998 e 2003.

Quando trazemos para nossas escolas todo o significado de inclusão, nos deparamos com uma realidade nada doce. Encontramos, em muitas instituições educacionais, barreiras carregadas de preconceito e ignorância. O despreparo e falta de conhecimento dos professores, gestores, pais na rede regular de ensino inibe e prejudica o processo de inclusão. Segundo Carvalho (2008, p. 38), 
a inclusão desafia, pois à mudança, estimula a flexibilidade das relações, a redistribuição dos recursos para um mais correcto aproveitamento, o trabalho em equipa, a colaboração e a cooperação, o envolvimento de toda a escola, dos pais, da comunidade, dos diferentes serviços e dos seus profissionais a montante e a jusante do sistema educativo.

Notamos que é fundamental a integração de todos da comunidade escolar - pais, professores, gestores, comunidade - em todo o processo de inclusão na escola regular das crianças com necessidades especiais. Percebe-se o quanto é rico e gratificante conviver com a diversidade, com as diferenças e proporcionar a todos um convívio de plena evolução pessoal e educativa, fazendo perceber que a diferença só enobrece a formação do cidadão.

Devemos compreender que não podemos simplesmente impor à inclusão nas escolas sem um preparo adequado. Isso requer uma reeducação dos profissionais da escola, sendo ofertados cursos, materiais educativos e o conhecimento das políticas públicas de inclusão e como estas vêm a atender os direitos dos alunos com necessidades especiais. Faz-se necessário que tenhamos em mente que o aluno, independente de possuir ou não uma necessidade, tem, acima de qualquer fator, direito à educação e ao acolhimento da escola, sem diferenciação entre elas.

Entende-se que as escolas que restringem o processo inclusivo são norteadas pelo preconceito ou pelo próprio medo de aderir ao movimento de inclusão. Medo este que vem da desinformação ou do receio em fracassar. O que acontece nos ambientes educacionais regulares é que estes são vistos como lugares de crianças ditas normais, nas quais as crianças com necessidades especiais não possuem vez. A instituição escolar deve repensar seu modo de agir e consolidar-se como um ambiente propício e favorável a desconstrução de toda e qualquer forma de discriminação.

Outro fator é a não aceitação de muitos pais ao processo de inclusão, pois acreditam que seus filhos serão prejudicados, já que na concepção destes o aluno com necessidade especial precisará de mais cuidados e atenção, deixando o restante da turma sem a atenção que teriam se fosse uma turma não inclusiva.

Para uma prática inclusiva ter êxito nossas escolas precisam estar preparadas em muitos sentidos como acessibilidade, profissionais formados na área da educação especial, psicólogos, salas especiais e muita receptividade aos alunos com necessidades especiais e suas famílias. Uma escola acolhedora cria um ambiente favorável não somente ao processo de inclusão, mas perante todo o resto, mas principalmente, a formação do seu aluno.

Rosa (2007) afirma que a igualdade está implicada no direito que esses sujeitos têm no processo de ensino-aprendizagem, respeitando sua individualidade e suas diferenças.

A mesma autora trabalha na perspectiva quântica, acreditando que vivemos numa sociedade como se fosse uma teia, inter-relacionando e interconectando os sujeitos nesta, e no momento em que ignoramos as pessoas com necessidades especiais, rompemos com esta teia e permitimos uma sociedade mais excludente. Não nos centramos em desenvolver as potencialidades que o ser humano tem e, no caso das crianças com necessidades especiais, mergulhamos no preconceito e na concepção errônea que estas não possuem potenciais e nem gabarito para aprimorar alguma 
aprendizagem.

Segundo Duek (2007), com a democratização do ensino, as escolas tiveram que repensar sobre si mesmas e nas suas convicções para compreender os anseios dos alunos especiais. Elas recebem o aluno para se inserir no processo inclusivo, mas muitas vezes, por falta de preparo ou até então, de descaso com a situação, acabam por fazer o movimento contrário ao de inclusão, provocando o isolamento deste aluno, assim, excluindo-o.

Um fator importante no processo de inclusão é a escola oportunizar para que ocorra a gestão de uma forma democrática, permitindo a comunidade auxiliá-la neste processo. O MEC (2011) esclarece que para que a inclusão ocorra de forma adequada é fundamental que os sistemas de ensino se transformem, com profissionais capacitados, e com a participação da família e comunidade, ou seja, é um conjunto de fatores que precisam ser levados em conta para que ocorra a inclusão de forma coerente e eficaz. Neste momento, o papel do professor em sala de aula é importantíssimo para o sucesso da inclusão do aluno especial. Atividades devem ser feitas de forma criativa e o ambiente especialmente criado para fazer eclodir todas as potencialidades da criança.

\section{Universo da educação infantil}

As crianças eram subordinadas apenas ao cuidado da família, mais especificamente, de suas mães e seu convívio permeava pela interação junto aos sujeitos pertencentes ao núcleo familiar. Com o movimento da industrialização, viu-se uma nova rotina nas famílias. Não somente os homens adentravam-se nas fábricas, mas também se inicia a inserção das mulheres no mundo do trabalho.

Inicialmente a solução encontrada pelas mães que entravam no mercado de trabalho como operárias das fábricas, era de deixar seus filhos com as chamadas mães mercenárias, que cuidavam dos filhos dos outros em troca de remuneração:

O nascimento da indústria moderna alterou profundamente a estrutura social vigente, modificando os hábitos e costumes das famílias. As mães operárias que não tinham com quem deixar seus filhos utilizavam o trabalho das conhecidas mães mercenárias. Essas, ao optarem pelo não trabalho nas fábricas, vendiam seus serviços para abrigarem e cuidarem dos filhos de outras mulheres. (Paschoal; Machado, 2009, p. 80)

Assim, notamos uma especificidade das famílias. Referindo-se mais particularmente ao Brasil, as creches foram criadas com caráter assistencialista, tendo como foco a ajuda às mães que trabalhavam fora e das viúvas que não tinham amparo, bem como os orfanatos que abrigavam os filhos das mulheres de vida ou de mães solteiras, que eram vistas com preconceito frente à sociedade. O caráter assistencialista é assim referenciado por Kuhlmann (2004, p. 183):

A educação assistencialista foi pensada no sentido de prever uma prática intencional, no interior de instituições constituídas para esse fim. A primeira característica a ressaltar dessa concepção educacional é que as instituições são defendidas por isolar as crianças de meios passíveis de contaminá-los, o principal deles, a rua. Em 1872, no Congresso Penitenciário Internacional, em Londres, já se apontava a importância das instituições educacionais para prevenir a criminalidade. No interior dos 
estabelecimentos, previam-se outras separações: por sexo, por idade e por grau de moralidade. A guarda então, era vista como um elemento ativo na educação dessas crianças.

O que Kuhlmann (2004) explicita é que cabia à educação assistencialista retirar as crianças de possíveis meios que pudessem corrompê-las e organizá-las para os cuidados da guarda. Porém, eram desencadeadas práticas e elementos que promovessem sua profissionalização futura e o cuidado com a dimensão da moral, ficando a questão intelectual em segundo plano.

A lei n. 9394/96 propõem uma nova proposta no contexto da educação infantil:

A Lei de Diretrizes de Base da Educação Nacional, Lei no 9394 de 20 de Dezembro de 1996, (LDB) coloca a criança como sujeito de direitos em vez de tratá-las, como ocorria nas leis anteriores a esta, como objeto de tutela. A mesma lei, proclama pela primeira vez na história das legislações brasileiras a Educação Infantil como direito das crianças de 0 - 6 anos e dever do Estado. Ou seja, todas as famílias que desejarem optar por partilhar com o Estado a educação e o cuidado de seus filhos deverão ser contempladas com vagas em creches e pré-escolas públicas. Outro objetivo contemplado pela Lei 9394/96, é o de que as instituições de Educação Infantil (creches e pré-escolas) fazem parte da Educação Básica, juntamente com o Ensino Fundamental e o Ensino Médio, em vez de permanecerem ligadas às Secretarias de Assistência Social. Nessa passagem das creches para as Secretarias de Educação dos Municípios esta articulada a compreensão de que as instituições de Educação Infantil têm por função educar e cuidar de forma indissociável e complementar das crianças de 0 a 6 anos. (Mathias; Paula, 2009, p. 14)

Pensa-se o quanto seria interessante e prazeroso se todos entendessem a educação infantil como um universo único, que antes dos conteúdos enfatiza a valorização das relações interpessoais e os ganhos que esta pode proporcionar e desencadear na formação da criança. A mesma oportuniza as crianças o convívio com diferentes pessoas e situações.

Um dos autores que podemos destacar no estudo da educação das crianças com deficiência ou com necessidades educacionais especiais é Lev S. Vygotsky (1896-1934). Mesmo sendo desenvolvida nos anos 1930, sua obra permanece atual e pode servir como subsídio para o desenvolvimento das práticas inclusivas das crianças com necessidades especiais.

Segundo Costa (2006,) Vygotsky não acreditava que o ser humano era imutável, mas que estava em constante processo de transformação e aquisição de novos conhecimentos e desafios. Partindo desse pressuposto de imutabilidade, muitos professores enxergam o movimento de inclusão das crianças com necessidades especiais como algo que não terá retorno, acreditando que estas crianças continuarão nas mesmas condições do momento de sua entrada numa classe regular e, nesse contexto, não concebe esta criança como um sujeito capaz de desenvolver suas potencialidades. Para Costa (2006),

Vygotsky deixa transparecer a sua crença na plasticidade - capacidade de se transformar do organismo e do ser humano - na capacidade do indivíduo de criar processos adaptativos com o intuito de superar os 
impedimentos que encontra. Apesar de o organismo possuir, em potencial, essa capacidade de superação, ela só se realiza a partir da interação com fatores ambientais, pois o desenvolvimento se dá no entrelaçamento de fatores externos e internos. (Costa, 2006, p. 233)

Desta forma, nota-se que Vygotsky acreditava que a partir de desafios o ser humano é capaz de se superar e buscar seu crescimento: "Vygotsky nos fornece as bases dessa concepção ao postular que a inteligência não é inata, mas se constrói nas trocas constantes com o meio ambiente" (Costa, 2006, p. 234). Assim, postulando a partir do meio social que a escola está inserida, esta pode construir mediações que enriquecerá tanto a criança especial como a dita normal a desenvolver suas destrezas através de trocas entre os colegas, com os professores e todos os sujeitos envolvidos dentro do contexto da escola.

O contexto escolar é um grande estimulador e influenciador do desenvolvimento das crianças, possibilitando inúmeras trocas, compartilhamentos, interações, consolidando num ambiente heterogêneo onde as diferenças e diversidades se aflorarão a todo o momento.

\section{Adentrando no campo investigativo}

Como explicitado anteriormente, o presente estudo teve o intuito de entender como acontece o processo de inclusão numa escola municipal de educação infantil, localizada no município de Santa Maria, Rio Grande do Sul.

Para vislumbrar bem as situações foi denominada a escola, as docentes e a gestora por nomes fictícios. Ficando então, nomeadas por nomes de flores ou árvores: Escola Girassol (escola municipal de educação infantil), Rosa (docente 1); Azaléia (docente 2); Orquídea (docente 3); Violeta (docente 4); Margarida (docente 5); Samambaia (docente 6) e Laranjeira (gestora).

$\mathrm{Na}$ escola Girassol há 10 crianças com diferentes necessidades especiais. Estas crianças são atendidas "pela educadora especial estando nas salas de aulas regulares. A mesma auxilia e orienta o corpo docente nos seus trabalhos com as diferentes inclusões que freqüentam a escola" (Informação extraída do blog da escola, disponível em http://docasuloaborboletasm.blogspot.com.br). A gestora da Escola Girassol complementa a informação destacando que a educadora especial da instituição tem uma carga horária semanal de 30 horas. Realiza atendimentos individuais na sala multifuncional e na turma da criança com colegas e professoras.

Pode-se perceber que a gestora Laranjeira, em sua afirmação, permite que possamos refletir sobre as políticas públicas de educação (ECA, 1990; LDB; PNE, 2001,) nas quais destacam a inclusão das crianças com necessidades especiais preferencialmente em salas regulares.

Nas referidas atitudes iniciais que são oferecidas pela escola quando acolhe um aluno com necessidade especial, a gestora afirmou que são realizadas entrevistas com os pais, professora e educadora especial. Pela entrevista busca-se diálogo sobre suas intenções e externem o que esperam para este processo de inclusão.

Já em relação ao suporte da escola para o atendimento deste aluno, a gestora relatou que 
a escola tem uma educadora especial com 30 horas semanais, possui uma sala multifuncional com materiais pedagógicos adaptados a algumas deficiências, todas as turmas têm estagiárias; ainda não temos acessibilidade para deficientes físicos por problemas burocráticos; participamos anualmente do curso sobre inclusão oferecido pela Secretaria Municipal de Educação e realizamos estudos em reuniões pedagógicas.

No tocante das respostas das pesquisadas nos questionários, notamos um empecilho que não somente se concretiza nesta escola, mas em tantas outras em nosso país: a burocratização intervindo nas situações que poderiam de certa forma ser desencadeadas de uma forma mais simples, evitando a demora em questões de suma importância, como a questão da acessibilidade neste caso.

A formação sobre ao assunto, mesmo que realizada uma vez ao ano, entra em consonância com novas discussões que sempre se caracterizam de uma nova experiência e relatos sobre as vivências de docentes com crianças especiais, tornando uma troca que favorece o enriquecimento de elementos que alimentarão ainda mais suas práticas com estas crianças com necessidades especiais.

A respeito da formação acadêmica das docentes da escola, notou-se que todas as participantes da pesquisa são pedagogas. Destacaram que participam de cursos sobre inclusão oferecidos pela Secretaria Municipal de Educação. Somente uma das participantes tem uma característica diferenciada e possui especialização em psicopedagogia, abordando em sua monografia a questão da inclusão e as contribuições que pode vir a ter o psicopedagogo neste processo no contexto da educação infantil.

Ao referenciar as políticas públicas, uma das questões apontadas no questionário foi a respeito do conhecimento em relação ao processo de inclusão nas políticas públicas nacionais, estaduais e municipais de inclusão e quais seus entendimentos sobre as mesmas:

Segundo a $L D B$ 9.394/96, toda e qualquer criança pequena (de 0 a 6 anos), tem direito de frequentar a escola. A escola deverá fazer as devidas adaptações para sua clientela. O aluno incluso poderá frequentar o turno oposto a sua aula, para atendimento com a educadora especial (Rosa).

Penso que as políticas públicas de inclusão são propostas que revelam a intenção de garantir educação para todos, compromisso do governo do município, do estado e da federação juntamente com a escola e os professores (Azaléia).

Muito pouco, na verdade procuramos saber quando a inclusão aparece na sala de aula. Hoje temos duas meninas inclusas e aos poucos estou me informando sobre as necessidades delas e o que as ampara (Violeta).

O que se percebe nas respostas é que os docentes salientam, constantemente, a questão da inclusão entrelaçada com o direito da criança com necessidade especial de frequentar uma escola regular e da possibilidade de uma classe especial em turno oposto a aula do discente.

A impressão que fica é que nossos professores, em termos de inclusão, necessitam 
de maiores detalhamentos e entendimentos em relação às políticas públicas, pois as leis que asseguram o direito das crianças com necessidades especiais referendam outros dispositivos que vão além destes apontados pelas docentes. Há um leque maior de saberes e conhecimentos que o corpo docente precisa estar ciente que necessita de um detalhar mais apurado, pois quando temos conhecimento aprofundado a respeito de um assunto, no caso, as leis que abordam a inclusão, vamos ter maior discernimento em fazê-las valer.

Em relação de como acontece o processo de inclusão das crianças com necessidades especiais na educação infantil, algumas professoras retrataram como um processo tranquilo.

Vislumbra-se que esse entendimento se volta a possibilidade que a educação infantil permite as professoras trabalhar com as diferenças sem o preconceito dos demais alunos pelos colegas especiais. As crianças estão no processo de apropriação de conhecimentos, aprendizagens, socializações, relações interpessoais. Entende-se que nesse ambiente se torna propício a inserção de aprendizagens às vezes bastante iniciais e ter um colega diferente permite a criança entender essa diferença como algo normal.

Para as docentes Orquídea e Azaléia, o processo de inclusão deve remeter há várias questões:

Penso que a inclusão necessita de estratégias frente às dificuldades para não se tornar um objeto único de socializar. Eis o grande desafio de quem está ali na sala de aula, tornar a aprendizagem significativa tanto para a turma regular quanto para o aluno incluso [...] preocupar-se com o número de crianças em sala, o atendimento humanamente coerente com o trabalho de qualidade e a preocupação com o "como" conseguir atender satisfatoriamente deveriam pesar muito ao se considerar o limite de alunos/classe. (Orquídea)

Depende muito do tipo de deficiência, da estrutura da escola, do professor que irá trabalhar com aquela inclusão, caso a escola e o professor não estiverem preparados nada acontece, mas se for ao contrário penso que é importante para a criança deficiente e também para os outros, pois terão oportunidade de trabalhar e conviver com as diferenças, entre as crianças não existe preconceito, elas aceitam, respeitam e ajudam o colega deficiente. (Azaléia)

A docente Orquídea nos possibilita refletirmos sobre a socialização. Muitas escolas focalizam suas atenções neste tema na educação infantil e, acaba por ficar amarrada a este objetivo, por vezes, se despreocupando com o restante que se faz importante como a infraestrutura da escola, os materiais pedagógicos que dispõem aos docentes, a acessibilidade, o número de alunos por turma.

Oliveira (1992, p. 64) aponta a creche como uma das variantes de desenvolvimento dos pequenos e salienta que a mesma deve estipular seu espaço de atuação:

A creche é um dos contextos de desenvolvimento das crianças. Além de prestar cuidados físicos, ela cria condições para seu desenvolvimento cognitivo, simbólico, social e emocional [...] Nela se dá o cuidado e a educação das crianças, que aí vivem, convivem, exploram, conhecem, construindo uma visão de mundo e de si mesmas, constituindo-se como 
sujeitos. Para uma ação efetiva, a proposta pedagógica deve considerar o conjunto de fatores interagindo na creche e definindo a atuação: as concepções de creche dos funcionários e das famílias, as condições do espaço físico, o tamanho do grupo e a razão adulto-criança, as atividades que implementa e os recursos que para tanto utiliza, os critérios de admissão das crianças, o número e o tipo de funcionários que dispõe, os processos de seleção e treinamento dos mesmos e as suas condições de trabalho.

Oliveira (1992) abre espaço para a reflexão de que toda a instituição escolar precisa revisitar alguns pontos fundamentais. Como pensa e articula a escola, quais as percepções dos docentes sobre a escola como um todo, o olhar atento a tudo que se passa dentro do ambiente educacional. Transpondo para o processo de inclusão, de que maneira as escolas entendem e até que ponto compreendem o posicionamento de seus docentes a respeito do processo e como se comportariam frente ao aluno incluído? Que subsídios a escola poderia prestar para que esta inclusão não acabe por gerar uma prática equivocada?

Um professor que não aceita o processo de inclusão, por medo de fracassar ou de não saber como voltar a sua prática docente frente ao aluno incluído, poderá trazer um desconforto. Por isso se torna imprescindível que a escola, sua equipe gestora identifique seu docente em diferentes percepções, para que numa situação de inclusão procure reavaliar com o docente que possui o receio de receber a criança especial, como ele poderia fazer a diferença para este aluno, da riqueza em vivenciar com o novo, de como é bom enquanto professor termos um desafio, uma provocação.

Outro questionamento para as docentes foi como percebem seu aluno incluído. Nesta questão podemos fazer a tentativa de compreender suas leituras, seus desdobres, suas articulações, suas posturas perante as crianças especiais:

Alguém que necessita muito do meu trabalho para se desenvolver plenamente. Um ser capaz de evoluir mesmo que de maneira mais demorada, principalmente, uma pessoa que precisa ser conhecida para depois eu conseguir atendê-la. Acredito que cada criança é única, mas não posso pensar em incluso como um parâmetro,é preciso identificar as necessidades para atendê-las (Orquídea).

Percebo que os alunos inclusos progridem significativamente, cada um a seu ritmo, aos estímulos da professora (Rosa).

Percebo como qualquer outra criança, tranquilamente. O que procuro sempre observar é: capacidades, características, dificuldades, enfim, o seu nível de desenvolvimento. Para que eu possa desenvolver as atividades em que esse aluno possa participa como qualquer outra criança, pois procuro sempre considerá-lo igualmente (percebendo sim suas diferenças) (Margarida).

Da mesma maneira que os outros. Adapto o trabalho proposto a necessidade do aluno, a criança tem seu tempo respeitado em qualquer circunstância (Violeta).

As palavras qualquer outra e da mesma maneira presentes nos discursos apontam Regae: Rev. Gest. Aval. Educ. Santa Maria v. 3 n. 8 Jul./dez. 2014 p. 83-98 
para a não diferenciação por parte das docentes sobre a criança especial, considerando-a como um fato normal e cotidiano de sua prática docente.

Outra apreciação que podemos observar nas palavras seu ritmo e seu tempo é que estas possuem o mesmo sentido, mas com sujeitos diferentes. A primeira aponta para a criança especial analisando que esta possui um ritmo menor e precisa ser considerado pelo docente que possua um aluno incluído. Já o seu tempo aponta para o tempo de toda criança, que estas precisam de um espaço para compreender, assimilar e se apropriar dos saberes que estão sendo imbricados, assim não somente rotulando a criança especial como único sujeito que necessite de um tempo determinado.

Ainda, torna-se importante destacar que as expressões trazidas pelas professoras remetem a idéia de padrão de ritmo, padrão de tempo, o que revela resquícios de uma educação homogênea que vê e percebe o outro a partir de um padrão específico.

De outra forma, as palavras única e igualmente podem indicar que a criança tem sua peculiaridade, sua característica comum, porém, direitos e deveres iguais a quaisquer sujeitos independentes de sua necessidade especial, cor, etnia ou classe social.

O que percebemos com estas respostas é que estes docentes pertencentes a Escola Girassol compreendem e dialogam sobre o processo de inclusão de uma maneira aberta e direta, sem medo de serem julgadas em suas práticas docentes. Isto fica claro na manifestação que segue:

Fico muitas vezes angustiada, tenho uma menina cega na turma e as vezes não sei o que fazer, falta material, a sala e os materiais não são adequados. Gostaria de fazer esta pergunta para minha aluna, Como ela se sente em sala de aula? Tenho confeccionado alguns materiais em alto relevo para ela, mas não é só isso, é todo um contexto que leva o professor, muitas vezes, a esquecer, por alguns minutos do seu aluno. Vejo a minha aluna não como um atrapalho, mas como um desafio, as vezes penso como fazer?

Sentimento de impotência é presente e eloquente em muitos docentes em nossas escolas. A fraqueza que sentem no momento que não conseguem atingir seu objetivo em relação ao seu aluno. As condições precárias que encontram no seu dia a dia. A demanda às vezes, acintosas de alunos nas salas e o esquecimento pela abrangência de muitas atenções que necessitam dar.

O como fazer que a docente Azaléia expõe faz questionar junto a professora: Em que espaços estão nossos governantes que não fazem cumprir as tantas leis que asseguram a dignidade de nossos alunos? Para que tantas leis se poucos usos lhes são proporcionadas? Será que precisamos passar por essa sensação com sabor de amargura?

Diante das outras inclusões de crianças com necessidades especiais que as docentes presenciam diariamente em sua docência e de como notam estas, se posicionaram da seguinte maneira:

Com certeza elas tiveram um crescimento, pois são nossos alunos a algum tempo e terão mais desenvolvimento, mas penso que se tudo fosse mais adequado, se as famílias fossem mais comprometidas esse processo teria uma evolução bem melhor (Azaléia). 
Acredito que as crianças vivenciam esta situação de maneira natural, sem marcar a diferença com impasse, inclusive ajudam as colegas na hora do aperto, alcançando as coisas nas mãos da cadeirante ou se identificando para a cega, essas atitudes tornam a inclusão uma situação natural, pleno de atitudes espontâneas, de carinho e respeito (Violeta).

A nossa escola tem crianças incluídas há alguns anos, então percebo todos muito adaptados com essa realidade, proporcionando um progresso grande e contínuo no desenvolvimento geral dessas crianças (cognitivo, social, intelectual) (Samambaia).

Uma vertente dessas respostas é a constatação da normalidade, tanto por parte dos docentes que participaram da pesquisa, quanto as crianças que não possuam a necessidade especial. Estes sujeitos lidam com a inclusão como uma convivência marcada pelo respeito, a troca de carinho, apreço e o cuidado pelo outro par.

As atitudes positivas das famílias das crianças com necessidades especiais, como por exemplo, acompanhamento de como está acontecendo o processo de inclusão de seus filhos no ambiente educacional, retratam em algumas situações em descaso. Esse comprometimento que a docente Azaléia traz em seu discurso falta por parte das famílias das crianças com necessidades especiais.

A apreciação dos dados dos questionários aponta a necessidade da reflexão e a importância de, para além desta, avaliarmos cotidianamente nossa prática e atitudes dentro da sala de aula. A importância de estarmos sempre nos revisitando e nos permitir renovar a cada instante em nossa docência. Dessa renovação, que seja pensada e voltada para a formação continuada e na troca e compartilhamento com seu colega professor. Contar suas vivências e experiências com o outro enriquece o processo educacional e fortalecem os laços de amizade, respeito e comprometimento com o próximo.

Neste sentido, se torna fundamental a presença de uma equipe gestora que esteja sempre resguardando os professores, auxiliando-os, dando suporte, ouvindo-os e prontos para qualquer intervenção caso seja necessário.

O processo de inclusão vem ao encontro de uma renovação em nossas escolas, fazendo-as repensar suas intenções, objetivos e que sujeitos pretendem formar. Também precisamos ter presentes a nossa docência, a procura constante de novos saberes, a curiosidade pelo desconhecido, a pesquisa, a reflexão crítica sobre a prática. Se escolhemos a profissão de professor, não podemos nos acomodar nunca, mas sim tentar fazer o melhor para o ensino/aprendizagem de nosso aluno, para sua formação crítica e enquanto cidadão. Ser professor é a busca incansável de soluções, alternativas em prol de nosso alunado.

\section{Considerações finais}

O espaço da educação infantil proporciona que o tema inclusão seja abordado de uma maneira mais serena e leve. Um ambiente que propicia trabalhar juntamente com as crianças e a diversidade só enriquece nosso universo. Trocar estas idéias já na infância com a criança permite que ela vá construindo estes valores de respeito ao outro desde pequenos e ter um colega com necessidade especial nesta etapa da educação só trará riquezas e enobrecerá a afetividade entre as crianças, brotando nas que possuem 
necessidades especiais a não inferioridade frente as demais e, criando um círculo de amizade, respeito e afeto entre elas.

Com a investigação realizada notou-se que as docentes da Escola Girassol, assim como a gestora da mesma, abraçam o processo de inclusão e tentam trabalhar com essa nossa constância a partir das condições que lhe são cabíveis e permitidas.

Uma escola que atende seus alunos sem vislumbre de preconceito, visto que na mesma há mais de dez crianças com diferentes necessidades especiais incluídas e estas são assistidas pelos professores de uma forma atenciosa e com todos os esforços para que estes alunos especiais sintam-se acolhidos e pertencentes em frequentar uma classe regular como qualquer outra criança dita normal.

Ao adentrar nas respostas das docentes da instituição, percebe-se que estes procuram informações principalmente dos alunos que estão incluídos na escola e com os quais trabalham. Buscam conhecimentos daquela necessidade especial, de como proceder nas atividades na sala de aula, contando com o suporte da educadora especial quando se faz necessário.

Em relação à educadora especial da instituição, esta desenvolve seu trabalho em uma sala multifuncional, tendo como suporte para desempenhar suas atividades pedagógicas com as crianças com necessidades especiais materiais adaptados. Os atendimentos acontecem quando necessários individualmente na própria sala. A educadora especial orienta as docentes da Escola Girassol em suas dúvidas e anseios, sempre estando disponível em qualquer circunstancias que lhe for solicitada.

A respeito dos conhecimentos sobre as políticas públicas, se percebe que as docentes, quando recebem um aluno incluído, não procuram em leis que enfatizam o processo de inclusão, sua maior preocupação está em conhecer mais sobre a criança que esta recebendo, buscando saberes mais específicos da necessidade especial de seu aluno.

Entendo que a inclusão é possível e desejável, isto é clarificado não somente nesta escola, mas em outras que tive a oportunidade de conhecer o processo de inclusão. Cada vez tenho mais certeza que para que a inclusão realmente se concretize, precisamos de passos a ser conquistados a cada etapa como: 1) a aceitação pelos pais de crianças especiais que estas podem sim frequentar um escola regular; 2) a escola aceitar este aluno de uma forma acolhedora e sem resquícios de discriminação; 3) a união de pais, professores, alunos, educadores especiais e gestores para que este processo tenha êxito; $4)$ procura pelo conhecimento das políticas públicas que tangenciam o processo de inclusão; 5) formação continuada de professores e gestores na área de inclusão; 6) acessibilidade; 7 ) equipe diretiva que busque incansavelmente melhorias dentro da escola para receber o aluno especial e que saiba utilizar dos dispositivos legais para garantir os direitos de seu alunado.

Escolas que possuem estes elementos abrem um caminho diferenciado para o processo de inclusão, contudo, também poderão encontrar em sua jornada muitos percalços, desafios constantes, mas que no fim se desabrochará em um trilhar doce, enriquecedor de muitas conquistas e vitórias. 


\section{Referências}

BARBOSA, Maria Carmen Silveira; BANDEIRA, Larisa; GOBATTO, Carolina. Mapeando alguns desafios para as políticas públicas de educação infantil no Brasil. ESCOLA DE INVERNO, 6, 1998. Anais. Porto Alegre: UFRGS, 1998.

BRASIL. Constituição da República Federativa do Brasil. Brasília: Senado Federal, 1988.

BRASIL. Ministério da Educação e Cultura. Disponível em http://portal.mec.gov.br. Acesso em: 23 ago., 2011.

BRASIL. Lei das Diretrizes e Bases da Educação. Disponível em http://portal.mec.gov.br. Acesso em: 11 out., 2011.

BRASIL. Marcos político-legais da educação especial na perspectiva da educação inclusiva. Brasília: MEC, 2010.

CARVALHO, Francisco. Reflexões em torno da inclusão em contexto educativo. In: FREITAS, Soraia Napoleão (org.). Tendências contemporâneas de inclusão. Santa Maria: UFSM, 2008, p. 31-47.

COSTA, Dóris Anita Freire. Superando limites: a contribuição de Vygotsky para a Educação Especial. Revista Psicopedagogia, v. 23, n. 72, 2006, p. 232-240.

DUEK, Viviane Preichardt. Um olhar sobre a deficiência/diferença na escola inclusiva. Revista Educação Especial, n. 29, 2007, p. 33-44.

FREIRE, Paulo. Pedagogia da autonomia: saberes necessários à prática educativa. São Paulo: Paz e Terra, 2006.

GIL, Antônio Carlos. Métodos e técnicas de pesquisa social. São Paulo: Atlas, 1999.

KUHLMANN JR., Moisés. Infância e educação infantil: uma abordagem histórica. Porto Alegre: Mediação, 2004.

LÜCK, Heloísa. Concepções e processos democráticos de gestão educacional. Petropólis: Vozes, 2006.

LÜDKE, Menga; ANDRÉ, Marli. Pesquisa em educação: abordagens qualitativas. São Paulo: EPU, 1986.

MACÊDO, Janaína Amanda Sobral. Inclusão: a escola está preparada para ela? Portal R7, Brasil Escola, Meu artigo. Disponível em <http://meuartigo.brasilescola.com/ educacao/inclusao-escola-esta-preparada-para-ela.htm>. Acesso em 20 mar., 2012.

MATHIAS, Elaine Cristina Bio; PAULA, Sandra Nazareth de. A educação infantil no Brasil: avanços, desafios e políticas públicas. Revista Interfaces: ensino, pesquisa e extensão. ano 1, n. 1, 2009, p. 13-16.

OLIVEIRA, Zilma de Moraes. Creches: crianças, faz de conta \& cia. Petrópolis: Vozes, 1992.

PASCHOAL, Jaqueline Delgado; MACHADO, Maria Cristina G. A história da educação infantil no Brasil: avanços, retrocessos e desafios dessa modalidade educacional. Revista HISTEDBR On-line, Campinas, n. 33, 2009, p. 78-95.

ROSA, Ângela Coronel da. Compreendendo o paradigma da inclusão. Revista Educação Especial, n. 29, 2007, p. 23-32.

UNESCO. Declaração mundial sobre educação para todos: satisfação das necessidades básicas de aprendizagem. Jomtien, 1990. 
UNESCO. Educação para Todos: O compromisso de Dakar. Brasília: Unesco, Consed, Ação Educativa, 2001.

UNESCO. Declaração de Salamanca, 1994.

UNESCO. Enquadramento da Acção, 1994.

VYGOTSKY, Lev Semenovith. Fundamentos de Defectologia. Havana: Pueblo y Educácion, 1989.

Luana Cardoso da Silva é graduada em Pedagogia Licenciatura Plena e especialista em Gestão Educacional pela Universidade Federal de Santa Maria. Atualmente trabalha como pedagoga na Apae Floriano Peixoto Pinto em São Sepé/RS.

Endereço: Almerindo Borba, 307 - 97340-000 - São Sepé - RS - Brasil.

E-mail: luanacardoso 86@yahoo.com.br.

Graziela Escandiel de Lima é professora na Universidade Federal de Santa Maria. Tem doutorado em Educação pela Pontifícia Universidade Católica do Rio Grande do Sul e atua, principalmente, com os seguintes temas: infância, educação infantil, trabalho pedagógico, docência e estágios.

Endereço: UFSM, Centro de Educação, Departamento de Metodologia do Ensino. Avenida Roraima, 1000 - prédio 16 - 97105-900 - Santa Maria - RS - Brasil.

E-mail: anahgrazzix@hotmail.com.

Recebido em 13 de maio de 2014.

Aceito em 27 de junho de 2014. 